\title{
Flat Layouts and Children Outdoor Activities
}

\author{
Azhan Abdul Aziz'1, Abdullah Sani Ahmad² \\ ${ }^{1}$ Faculty of Architecture, Planning and Surveying, Universiti Teknologi MARA, Perak \\ 2Faculty of Built Environment, Universiti Teknologi Malaysia, Skudai \\ absani@utm.my
}

\begin{abstract}
In Malaysia's urban peripheries, where residential development still has room to expand, walk up flats have become a popular form of low cost housing because of their relatively low construction and maintenance costs to match the required demand of the increasing urban poor. In this housing type, standardization and spatial efficiency results in minimum dwelling space, causing life to spill to the outdoors which then become vital social space for children. Appropriations of the space are an integral part of children's growing up and social experiences. The paper explores the differences in children outdoor activities near the homes in relation to the different low cost flat layouts through a comparative observational study. Different flat configurations were found to offer different spatial affordances for children's social experiences which could inform design decisions.
\end{abstract}

Keywords: low cost flats, outdoor space, children activities

eISSN 2514-751X @ 2017 The Authors. Published for AMER ABRA by e-International Publishing House, Ltd., UK.. This is an open access article under the CC BY-NC-ND license (http://creativecommons.org/licenses/by-ncnd/4.0/). Peer-review under responsibility of AMER (Association of Malaysian Environment-Behaviour Researchers), ABRA (Association of Behavioural Researchers on Asians) and cE-Bs (Centre for EnvironmentBehaviour Studies), Faculty of Architecture, Planning \& Surveying, Universiti Teknologi MARA, Malaysia.

https://doi.org/10.21834/aje-bs.v2i3.189 


\subsection{Introduction}

Continued urbanization in Malaysian cities boosts the demand for housing the urban poor. In the urban peripheries, walk up flats become preferred types of low cost housing compared to high rise flats as the former incur lower costs of construction and maintenance (Long, 2007; Tan, 1979). In contrast to low cost terrace with direct access to ample ground areas, walk up flats are usually built on constraint land and green areas. Dwelling spaces of walk up flats are also limited as they are designed based on standardization and economic efficiency. Inevitably, the outdoor and circulation spaces near the homes turn into vital social place particularly for children. Besides schools, near home spaces are arenas for developing their knowledge and social skills (van Vliet, 1983). This paper explores how the different flats configurations affect children's appropriation of the outdoor space for social and retreat activities.

\subsection{Literature Review}

Studies on impacts of physical environment on children reveal mixed evidence (van Vliet, 1983). High rise buildings were found to relate to higher incidence of children problematic behaviours (Saegert, 1982). Such housing is also associated with weaker academic performance (Oda, Taniguchi, Wen, \& Higurashi, 1989). High density of multi-family housing too were found to relate to a higher rate of juvenile delinquency (Gillis, 1977). However, past literatures also point to the important roles of built environment on children activities and social experiences which constitute an integral part of their growing up process (Evans, 2006).The outdoor environment could contribute to children's life experiences and influence their well being. The longer the outdoor experience they have, the higher learning benefits they acquire (Hattie, Marsh, Neill, \& Richards, 1997).

Constrain of outdoor space may cause tension and isolation for children and their mothers (Churchman \& Ginsberg, 1984). Housing areas also provide potentials for social support in bringing up children depending upon good neighbour relations. Less support due to poor neighbourly relations contribute to a disruption in children development (Evans, 2006). In low income housing, the effects of a lack in social support are more apparent.

Children prefer natural outdoor setting as it offers wider potentials for motor and social play (Evans, 2006). Such natural environments afford greater independence and mobility (Kyttä, 2004), and more complex play types (Kirkby, 1989). Children also play and socialize more in natural surroundings than in a more barren environment (Taylor, Wiley, Kuo, \& Sullivan, 1998). While neighbourhood planning emphasizes provision of playground and open space, researches have shown that they are minimally used and contribute little to local social interaction (Abu-Ghazzeh, 1999). This is partly due to the inconvenient locations that are away from parental surveillance. Outdoor near home spaces become convenient alternative. 
Moreover, in low cost flats, opportunities to be in a natural setting are limited due to the economic needs to optimize use of land area (Tan, 1979). Thus, living in low cost flats particularly constrains children's growing up needs and experiences. How they adapt to the lack of such setting andconsequently appropriate the available spaces remains underexplored.

Housing outdoor spaces are important environments for children in their development process depending upon the affordances of appropriate spaces for play and socialization. In low cost housing, constraints of space would disrupt their experiential opportunity. Alternatively, children need to adapt to the limited environment to make them more congruent (Kaplan, 1983). Research in housing should appreciate such adaptations to generate potentials for social experiences. Particularly, within the limited options in flats configurations, the different impacts of physical environment on outdoor activity should be well comprehended so that such design decisions do not hinder children's developmental processes.

\subsection{Methodology}

The paper explores the relationship between the different configurations of low cost flats and children use of outdoor spaces. Systematic behavioural observation was applied to three selected sites utilizing behavioural checklist. Age, ethnicity and gender of the observed subjects are recorded, and their behaviours are mapped by two observers along predefined routes. Reliability tests show $88.5 \%$ agreement on the behaviour observed and $94.9 \%$ agreement on the event activity type categorization. 22 observations done in each site cover every hour from 8 am to $6 \mathrm{pm}$ on both weekends and weekdays. Each observation lasts 3040 minutes and is distributed into 8 to 10 minutes in each block. Descriptive analysis of children outdoor activities is then presented.

\subsection{Introduction to study areas}

The study is done in the district of Johor Bahru, the capital of Johor state. In the Ninth Malaysia Plan, Johor expected to build the highest number of low cost housing $(91,500$ units) after Selangor (Government of Malaysia, 2005). Up to the third quarter of 2009, Johor Bahru, has a sum of 85,396 low cost units constituting $50.8 \%$ of all low cost units in the state. Of these, $46 \%(39,276$ units) are flats (NAPIC, 2009). After the third quarter, another 4,663 units of flats were expected to be built. More than 60 sites of low cost walk up flats were purposively sampled to control for building height, housing age, ethnic heterogeneity and population size. Three sites were selected to represent the most common flats configurations. Table 1 shows the comparison between the selected sites. 
Low cost flats 1 (LCF1) contains six blocks of flats with open air corridor forming courts occupied by parking spaces. Low cost flats 2 (LCF2) contains the same number of blocks, each with a narrow vertical air well that provides light and ventilation to four levels of internal corridors. Low cost flats 3 (LCF3) containing clusters of units organized around staircases, represents the most recent type. Each floor has minimal corridor space surrounded by four dwelling units. All areas contain six blocks of five-storey flats. LCF1 includes ground units while LCF2 and LCF3 are without the ground units. Instead, the latter two housing areas accommodate common covered ground court.

Table 1: Summary of study areas

\begin{tabular}{|c|c|c|c|}
\hline & LCF1 & ICF2 & LCF3 \\
\hline \multicolumn{4}{|l|}{ Belding eanfourafon } \\
\hline & Ofun aeridat & 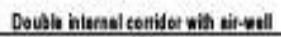 & Clustened araend thinesut \\
\hline Nunbet of ahis & 450 & 430 & 476 \\
\hline Dettiy & Bo unile pat hatio & 94 utih pat acen & 90.8 unils far tetil \\
\hline Nunbet of ants far host & 16 & 20 & 4 \\
\hline Unt th youad lewi & $\overline{Y a t}$ & Ho & No \\
\hline Oitued foet coveitd temean eauif & $N_{0}$ & $Y_{n}$ & $Y_{u t}$ \\
\hline Playesuta & $\mathrm{S}_{6}$ & Ho & $\overline{Y u}$ \\
\hline Year of otcupalion & 19976 & 20024 & 2000 \\
\hline 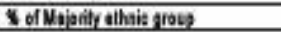 & 868 & $64 x$ & 725 \\
\hline
\end{tabular}

\subsection{Variables}

Two common categories of children activities (social and retreat) were identified as the most frequently observed. Social activity includes active group activities such as playing and talking, and less active ones such as brief encounters and greetings. Retreat activity consists of all solitude activities including playing alone, watching people and event in the surroundings, and relaxing (sitting or lying). General and domestic activities were noted for events that do not fit the above categories. Spatial hierarchical analysis of the housing plans identifies the corridor, staircases, covered common court, perimeter (green surfaces surrounding block), parking and vehicular routes as common spaces in the three housing areas.

The major assumption is that the territorial functions (Scheflen, 1976) of these spaces condition how people engage with their surroundings, and the outdoor spaces act as the juncture and connector between the private and the public realm. Structured by the layout, circulation, and formation of communal space, these spaces could provide opportunities for outdoor social life (Marcus, 2002). 


\subsection{Results and Discussions}

A total of 4,960 residents were observed and $55.4 \%$ of them were children ( $N=2,750)$.A total of 1,217 events involving children were recorded and $49 \%$ of those events involved children accompanied by adults. While more female adults $(65.6 \%)$ were observed compared to male adults, more boys $(62.9 \%)$ were seen around the outdoor areas than girls. Social activity encompasses $64.0 \%$ of all events observed. This shows that, contrary to recent studies (Huang, 2006), the outdoors near home spaces are fertile social spaces and the phenomenon of social withdrawal is not apparent at least in Malaysia's low cost residential environment. People do not entirely disregard the vernacular practices of neighbours. (Chua, 1991). Outdoor near home spaces serve as vital place with potentials for social encounters.

Table 2: Overall activity distributions

\begin{tabular}{|c|c|c|c|c|c|c|c|c|c|c|}
\hline \multirow[b]{2}{*}{ Types of activity } & \multicolumn{2}{|c|}{ LCF1 } & \multicolumn{2}{|c|}{ LCF2 } & \multicolumn{2}{|c|}{ LCF3 } & \multirow{2}{*}{$\frac{\text { Total }}{\mathrm{N}}$} & \multicolumn{3}{|c|}{ Chi Square } \\
\hline & $\begin{array}{l}\text { Whoin } \\
\text { housing }\end{array}$ & $\begin{array}{l}\text { Between } \\
\text { housings }\end{array}$ & $\begin{array}{l}\text { Within } \\
\text { housing }\end{array}$ & $\begin{array}{l}\text { Between } \\
\text { housings }\end{array}$ & $\begin{array}{l}\text { Whin } \\
\text { housing }\end{array}$ & $\begin{array}{l}\text { Befween } \\
\text { housings }\end{array}$ & & $x^{2}$ & of & 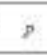 \\
\hline Domestic & $5.9 \%$ & $2.2 \%$ & 696 & $22 \%$ & $8.8 \%$ & $27 \%$ & 7.18 & 1.300 & 2 & 0.57 \\
\hline Retrest & $3.2 \%$ & $11.7 \%$ & 26.286 & $64 \%$ & $28.8 \%$ & $87 \%$ & $289 \%$ & 3.470 & 2 & 0.18 \\
\hline \multirow[t]{2}{*}{ Social } & $62.9 \%$ & $23.7 \%$ & $66.8 \%$ & 21.446 & $62.3 \mathrm{k}$ & $18.9 \%$ & $640 \%$ & 0.737 & 2 & 0.60 \\
\hline & $100.0 \%$ & $37.6 \%$ & $100.0 \%$ & $32.1 \%$ & $100.0 \%$ & $30.3 \%$ & $100.0 \%$ & & & \\
\hline
\end{tabular}

Table 3: Types of children's social and retreat activities

\begin{tabular}{|c|c|c|c|c|c|c|c|c|c|c|c|c|c|}
\hline & \multicolumn{3}{|c|}{ LCF1 } & \multicolumn{3}{|c|}{ LCF } & \multicolumn{3}{|c|}{ LCF] } & \multirow[t]{2}{*}{ Tocal } & \multicolumn{3}{|c|}{ Chisquare } \\
\hline & $\begin{array}{l}\text { Swhin } \\
\text { LCF }\end{array}$ & ${ }_{\text {quara }}^{8}$ & $\begin{array}{l}\text { Swhin } \\
\text { odvety }\end{array}$ & $\begin{array}{l}\text { Swhin } \\
\text { LCF }\end{array}$ & ${ }^{5}$ & $\begin{array}{l}\text { Swhin } \\
\text { cotain }\end{array}$ & 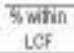 & के & $\begin{array}{l}\text { Switin } \\
\text { atoing }\end{array}$ & & $r^{3}$ & 4 & i \\
\hline \multicolumn{14}{|c|}{ Caildren Social Achity } \\
\hline Plaing in Growp & 59.78 & 2174 & 39.75 & 5098 & 12.46 & $329 \%$ & SASN & 17.96 & $\sin x$ & $50: \%$ & s.ra & 2 & (697 \\
\hline Taknolonumsing & 23.64 & 1226 & 34.76 & 31.78 & $102 \%$ & 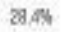 & 42.43 & 13. Aैh & $370 \%$ & $36.4 \%$ & 0.52 & 2 & $\cos { }^{\circ}$ \\
\hline Bns encourters & $\cos$ & $24 \pi$ & $46.7 \mathrm{~N}$ & 7.5 & $2+16$ & 16. 76 & $1.1 \%$ & $0.2 x$ & $6 \pi \mathrm{k}$ & 326 & m & 2 & $m$. \\
\hline Tow & 20006 & 5634 & & 20000 & 5205 & & 10000 & $917 \pi$ & & $9000 \%$ & & & \\
\hline \multicolumn{14}{|c|}{ Children Retreat Activity } \\
\hline Plajing ASTA & 2036 & 1744 & $34.7 \mathrm{~h}$ & 69.54 & $160 \%$ & 20,06 & $60.4 \%$ & $170 \%$ & 33.76 & $60.3 \%$ & 0.75 & 2 & oss \\
\hline Watting & 4174 & 1895 & 525N & 2184 & $6.0 \%$ & $1900 \mathrm{~s}$ & SGAS & $6.6 \%$ & 21,45 & $31.7 \%$ & 25 & 2 & $\tan \cdots$ \\
\hline Rolang & $6 x$ & $26 \%$ & $278 \%$ & 1094 & $a 0 m$ & $\%$ & $4.2 \%$ & $1.1 \%$ & $143 \%$ & 79.94 & $2 \pi$ & 2 & 2254 \\
\hline athis & $11.7 \mathrm{~s}$ & $5.3 \%$ & 6006 & 815 & $23 \%$ & 2406 & $700 \%$ & $19 \%$ & $200 \pi$ & 9.46 & & & \\
\hline Tows & soos & 45.96 & & 20005 & $27.0 \mathrm{ss}$ & & souss & Sters & & $9000 \mathrm{x}$ & & & \\
\hline
\end{tabular}

Initial analysis shows that children in different types of physical environment seem to have similar proportion of activities (Table 2). This could be attributed to the similarity of the lifestyle and the socioeconomic background of low income community. The results shore up trustworthiness of the sampling in accordance to previous studies relating homogeneity and social outdoor activities. Despite the different physical environment and location, children's activities and needs around the housing area tend to be similar. However, more specific analyses reveal significant differences between some of the activities (Table 3). Different 
physical contexts seem to affect the amount of group conversations and occurrences of brief encounters. Group conversations are significantly higher in LCF1 and LCF3 $(p<0.05)$. Prolonged conversation is significantly less in LCF2 $(28.4 \%, p<0.05)$ than in LCF1 $(34.1 \%)$ and in LCF3 (35.8\%). Brief encounters among children, however, are significantly higher in LCF1 and LCF2 $(p<0.05)$. Corridor spaces afford more movement of children and there is more potential for them to bump with each other. Watching is observed significantly more in LCF1 compared to the other two sites.

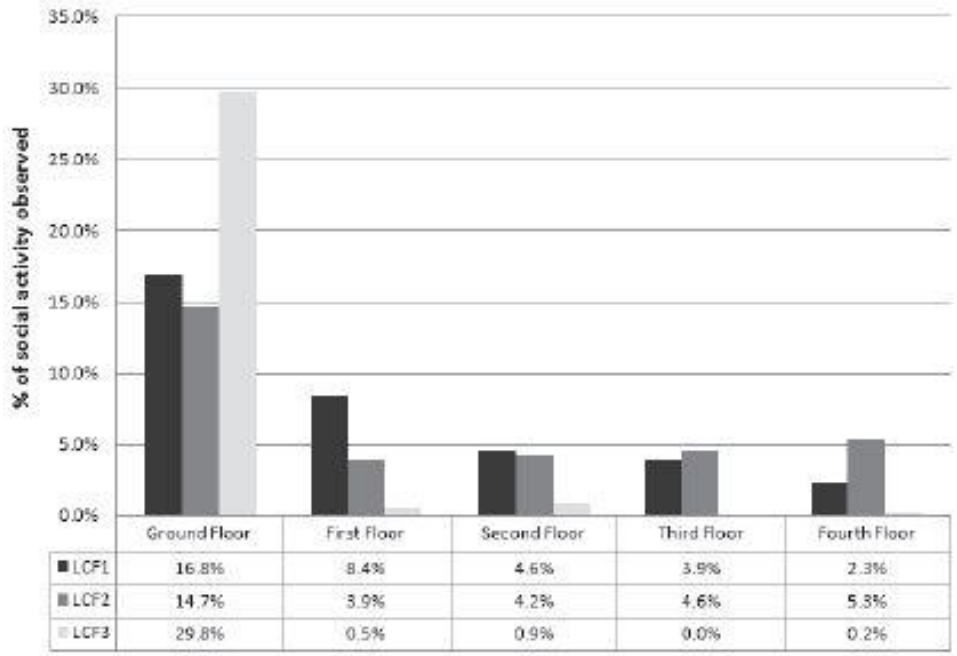

Figure 3: Social activity by floor levels

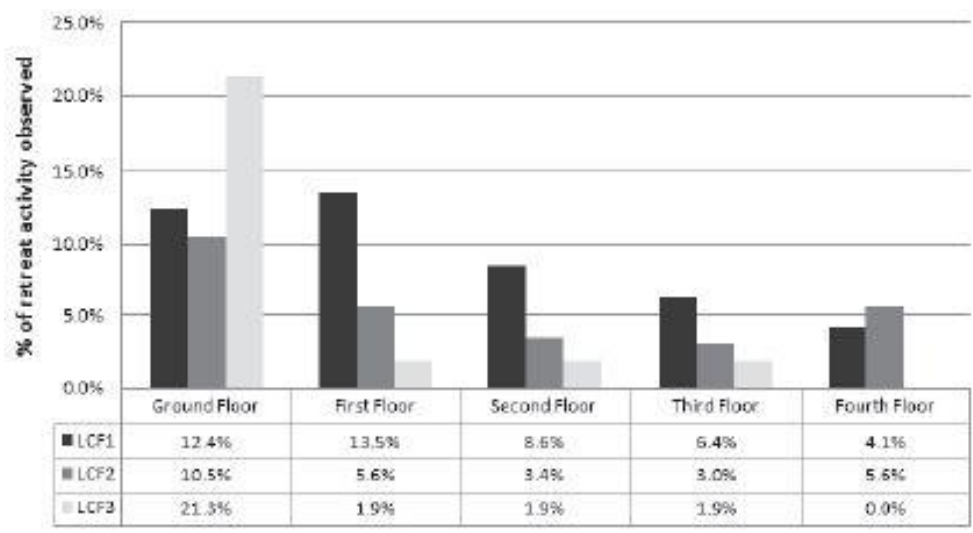

Figure 4: Retreat activity by floor levels 
Similar to other studies, activities generally decrease as floor level rises (Ginsberg \& Churchman, 1985). However, the rates vary by flat configurations. Comparison between the activity differences in the first to the fourth floor corridors of LCF1 and LCF2 shows a significant variation in social activities by the floor level in LCF $1\left(X^{2}=24.1, p=0.000\right)$, while it is not significant in LCF2 ( $\left.X^{2}=1.59, p=0.661\right)$. However, different characteristics of the ground floor do not display any significant different in the amount of social activity. In other words, having either ground floor units or common court does not significantly affect the amount of children socialization. In open corridors, however, rise in floor level significantly reduces socialization activity; children play and socialize more on the lower levels.

Significant differences in retreat activities were found between the different floor levels among the three sites (Figure 4). Such activity varies significantly by floor levels in LCF1, $\left(X^{2}=18.5, p=0.001\right)$. In LCF2, more retreat activities were observed in the first and the top floors than in those that were in between. Lack of view to watch in the middle levels, coupled with lower lighting could possibly hamper such activities. However the difference is not statistically significant $\left(X^{2}=3.64, p=0.303\right)$. Lack of space near the homes in LCF3 explains the concentration of activities on the ground level and the extremely low scores of in the upper levels. The common court and perimeter playground compensate the shortfalls.

\subsection{Spatial locations}

Generally, corridors of LCF1 and LCF2 accumulate the highest score in all events observed (44.7\%). In contrast, activities in LCF3 focus on the common court and perimeter. Small corridor space in LCF3 turns the ground level into active space ( $27 \%$ of all events). The provision of perimeter playground does add to the vitality of the ground space. On the other hand, less the ground common court, LCF3 only records $8.9 \%$ of all events observed. This conversely draws attention to the high score of activity recorded in the corridor of LCF1 $(26.8 \%)$. Variations of activities between the spatial locations of the three LCFs indicate statistical significance $(p<0.001)$ except for staircase $(p<0.5)$.

Table 4: Location of social and retreat activities

\begin{tabular}{|c|c|c|c|c|c|c|c|c|c|c|c|c|c|c|}
\hline \multirow{3}{*}{ Lacetion } & \multicolumn{7}{|c|}{ SOCDAL ACTIVTY } & \multicolumn{7}{|c|}{ EETREAT ACTNITY } \\
\hline & \multicolumn{2}{|c|}{ LEFa } & \multicolumn{2}{|c|}{$\operatorname{scr} 2$} & \multicolumn{2}{|c|}{ ters } & \multirow[b]{2}{*}{ Total } & \multicolumn{2}{|c|}{$\operatorname{Irn} 1$} & \multicolumn{2}{|c|}{ Lerz } & \multicolumn{2}{|c|}{ Lers } & \multirow[b]{2}{*}{ Total } \\
\hline & $\begin{array}{l}\text { Whtin } \\
\text { Lert }\end{array}$ & $\begin{array}{l}\text { Eescusen } \\
\text { Lofa }\end{array}$ & $\begin{array}{l}\text { Whan } \\
\text { Lef? }\end{array}$ & $\begin{array}{l}\text { Detweas } \\
\text { LCf: }\end{array}$ & $\begin{array}{l}\text { Wathin } \\
\text { iCra }\end{array}$ & $\begin{array}{l}\text { Eetwean } \\
\text { LCra }\end{array}$ & & $\begin{array}{l}\text { Whin } \\
\text { icri }\end{array}$ & $\begin{array}{l}\text { Detween } \\
\text { Lefra }\end{array}$ & $\begin{array}{l}\text { Wein } \\
\text { Lef2 }\end{array}$ & $\begin{array}{l}\text { Qdeswesn } \\
\text { LCry }\end{array}$ & $\begin{array}{l}\text { Wetrm } \\
\text { LCr3 }\end{array}$ & $\begin{array}{l}\text { Eetwens } \\
\text { LCfy }\end{array}$ & \\
\hline Parking & $252 \%$ & $20 \%$ & 1.48 & $0.5 \%$ & 5.43 & 1.74 & $11+k$ & $5.4 \%$ & $2.7 \%$ & $00 \%$ & $0.0 \%$ & 7.08 & $21 \%$ & 4.35 \\
\hline Perineter: & $7.2 \%$ & $20 \%$ & $4.3 \%$ & $1.4 \%$ & 2234 & 6.85 & $20.5 \mathrm{~s}$ & $1,4 \%$ & $0.0 \%$ & rox & $2,1 \%$ & $14 \mathrm{cs}$ & $4.3 \%$ & s.s \\
\hline Common Court & ats & $00 \%$ & 30.056 & 1004 & eass & $188 \%$ & $28, \pi$ & $00 \%$ & $0.0 \%$ & $25.9 \%$ & $9.0 \%$ & 57.95 & 17656 & $26.6 \%$ \\
\hline starcase & $2.6 \%$ & $0.7 \%$ & $7,1 \%$ & $24 \%$ & $10.0 \%$ & $3.15 \%$ & $6.2 x$ & $4.1 \%$ & $1.0 \%$ & $70 \%$ & $2.1 \%$ & 5.34 & $1.0 \%$ & 3.35 \\
\hline \multirow[t]{2}{*}{ Corribar } & $650 \%$ & 22.54 & 57.14 & 19.04 & 154 & D.5s & 4185 & $89.2 \%$ & $351 \%$ & $58.1 \%$ & $17.0 \%$ & $15.8 \%$ & C.BK & $\operatorname{sen}$ \\
\hline & $100.0 \mathrm{w}$ & 35.95 & 100.05 & 30.35 & $100.0 \%$ & $30.9 \%$ & $1000 \%$ & 100.05 & 39.46 & $1000 \mathrm{~s}$ & 30.35 & $100.0 \mathrm{~s}$ & $30.3 \%$ & $1000 \mathrm{x}$ \\
\hline
\end{tabular}

\section{Retreat activity}

Children were seen to play alone significantly more in LCF1 ( $X^{2}=2.21, p=0.332$ ) as $39.4 \%$ of the total observed retreat activities were recorded. Meanwhile, each LCF2 and LCF3 recorded $30.3 \%$ 
of the total retreat activities. All activities in retreat category record their highest scores in the corridors of LCF1 (Table 4). The open corridor, with abundant light, opens views to the streets and surroundings, and chance for surveillance seems to relate to more children being seen alone outside. Presence of people and events to see are important factors for outdoor activities (Holland, Clark, Katz, \& Peace, 2007; Jacobs, 2002; Marcus, 2002; Zhang \& Lawson, 2009). Such characteristics in the corridor of LCF1 contribute to the high retreat activity recorded $(89.2 \%$ of all retreat activities within the housing area). In contrast, the corridors of LCF2 and LCF3only hold $17.0 \%$ and $4.8 \%$ of the retreat activities. While both contain common courts, different types of retreat activities are afforded. Resting was recorded more in LCF2 while playing alone was recorded more in LCF3. Both however do not afford as much of watching behaviours as in LCF1 for such behaviours depend on available events and views.

Corridor is an important space for retreat activity. Even though observation shows that most outdoor activities, including retreat activities, concentrate in the covered ground common court as apparent in LCF3, given the choices of having both relatively bigger corridor and the provision of covered ground common court (as exemplified in LCF2), the children still chose to be in corridor and close to homes. In LCF2, retreat activities score $56.1 \%$ in the corridor compared to only $29.8 \%$ in the covered common court (Table 4). Children need to be accessible to their parents while playing. While the corridors of LCF2 scores high in resting and playing alone, its inward orientation to the narrow air well affects the low score of watching even compared to LCF3 which affords street view.

\section{Social activity}

Generally, LCF1 displays the highest number of social activity (Table 4). Even without the playground or covered common ground, children were observed to socialize more than in the other LCFs. Social activities happen mostly in the corridor and the courtyard (parking area) which receives direct surveillance from the surrounding residents. The U-shaped configuration allows parents to view their kids just by stepping out into the corridor. The findings also show that even without the provision of playground, social activities in LCF1 and LCF2 remains high; children play near their homes more. They explore alternative spaces to fulfil their socialization and retreat activities. The provision of playground does not necessarily increase the amount of children's activities.

Even though the common court turns out to be children's favourite social place in LCF3 $(60.8 \%)$, the figure only accounts for $18.8 \%$ of all social activity observed (Table 4$)$. The corridor remains as popular place in LCF1 $(23.5 \%)$ and LCF2 (19.0\%). Even the combined green perimeter and playground in LCF3, do not hold as much social activity. Nonetheless, the playground does compensate for the lack of corridor space LCF3. Spaces close to homes are still important social arena for children as $43 \%$ of all social activity was observed in the corridor. In LCF1 and LCF2, corridor displays $65.6 \%$ and $57.1 \%$ of social activities within respective areas; the lack of playground is in turn compensated. 


\subsection{Conclusion}

Outdoors near home spaces in low cost flats serve as important activity arenas for children. Such spaces right at the door front, though minimized for economic purposes, are ecologically important environments for children. Flats layouts affect not only the development cost, but also pattern of children activities and experiences. Different physical outdoor space offer diverse functional affordances. While the three sites have similar proportions of overall activity types and amount, closer analyses reveal significant variations pointing to the impacts of flats layouts. The provision of playground may satisfy children's needs for certain play types but does not increase children's outdoor activities. Neither lack of such space decreases those activities. Their exploratory nature drives them to search for alternatives. In turn, the outdoor circulation spaces become meaningful places for them. Their responses to dull environment are rational adaptations rather than misguided behaviours (Becker, 1976). Therefore, the factors of children social experiences might be closer to homes than we expected. In case of limited option in low cost housing development, flats layouts do provide the differences.

\section{Acknowledgement}

The study is made possible by Fundamental Research Grant Scheme and UTM. The Authors wish to thank the reviewers and acknowledge contributions of officers at MBJB, MPJBT, MPPG and NAPIC.

\section{References}

Abu-Ghazzeh, T. (1999). Housing layout, social interaction, and the place of contact in Abu-Nuseir, Jordan. Journal of Environmental Psychology, 19(1), 41-73.

Becker, F. D. (1976). Children's Play in Multifamily Housing Environment and Behavior, 8(4), 545-574.

Chua, B. (1991). Modernism and the vernacular: transformation of public spaces and social life in Singapore. Journal of Architectural and Planning Research, 8(3), 203-222.

Churchman, A., \& Ginsberg, Y. (1984). The image and experience of high rise housing in Israel. Journal of Environmental Psychology, 4(1), 27-41.

Evans, G. W. (2006). Child Development and the Physical Environment. Annual Review of Psychology, 57(1), 423451.

Gillis, A. R. (1977). High-rise housing and psychological strain. Journal of Health and Social Behavior, 18(December), 418-431.

Ginsberg, Y., \& Churchman, A. (1985). The pattern and meaning of neighbor relations in high-rise housing in Israel. Human Ecology, 13(4), 467-484. Government of Malaysia (2005). Ninth Malaysia Plan, 2006-2010. 
Hattie, J., Marsh, H., Neill, J., \& Richards, G. (1997). Adventure education and Outward Bound: Out-of-class experiences that make a lasting difference. Review of Educational Research, 43-87.

Holland, C., Clark, A., Katz, J., \& Peace, S. (2007). Social interactions in urban public places. Bristol, UK: Joseph Rowntree Foundation.

Huang, S. (2006). A study of outdoor interactional spaces in high-rise housing. Landscape and Urban Planning, 78(3), 193-204.

Jacobs, J. (2002). The Death and Life of Great American Cities. In G. Bridge \& S. Watson (Eds.), The Blackwell City Reader (pp. 351-356). New York Blackwell Publishing 